\title{
Retrospective Study on Dental Affections in Horses of Equestrian Clubs and their Possible Treatment
}

\section{Mostafa M Kassem, Ahmed S Korittum and Ahmed S Raslan*}

Department of Surgery, Faculty of Veterinary Medicine, Alexandria University, Egypt

*Corresponding Author: Ahmed S Raslan, Department of Surgery, Faculty of Veterinary Medicine, Alexandria University, Egypt.
Received: March 17, 2020

Published: April 30, 2020

(C) All rights are reserved by Ahmed S Raslan., et al.

\section{Abstract}

The present work was carried out in the period between "March 2015 to December 2016" the total number of examined horses was 354 horses, 92 horses 26\% had dental affections including 52 Equestrian horses, 34 Riding horses, 6 Funeral dragging horses. These horses were of both sexes and their ages were ranged between 3 years up to 22 years old. The examined horses were collected from Armed Equestrian club, El Gzera club, El haram farms, Cairo stadium, El Shams club and Wadi Degla club.

The horses were divided according to usage into 3 groups, first group was used as equestrian horses, second group was used as riding horses and third group was used as funeral dragging horses. First group involved 52 equestrian horses, 49 male horses and 3 female ones. Second group involved 34 riding horses, 13male horses and 21 female ones. Third group involved 6 funeral dragging horses, they all are male horses.

The examined horses in this study were subjected to comprehensive study including history, type of horse (Equestrian, Riding and Funeral dragging), the time of last floating, post treatment care and follow-up.

The prevalent dental affections in equestrian clubs that were found are dental tartar $81.52 \%$, sharp enamel points $42.39 \%$, dental caries $35.86 \%$, periodontal disease $19.57 \%$, rostral hook $16.30 \%$, diastmata (diastasis dentium) $16.30 \%$, incisor tooth fracture $6.52 \%$, parrot mouth $3.26 \%$, bit seat $3.26 \%$, caudal hook $3.26 \%$ and canine tooth fracture $1.087 \%$.

Periodical examination is essential in detection and treatment of dental affections; furthermore, using of power float, mouthwashes, curetting of teeth and extraction of teeth gave good results in treatment of these dental affections Neglecting the treatment of dental tartar, sharp enamel points, dental caries, periodontal disease, diastmata, bit seat and caudal hook resulted in some complications as equine colic and ulcer.

Keywords: Retrospective; Equestrian; clubs; Dental and Affections

\section{Introduction}

Dental disease is the main oral disorder of horses and is of major importance in equine veterinary practice, with up to $10 \%$ of practice time involving dental-related work [1].

The purpose of the equine dental examination is to determine a pathologic condition exists and to evaluate its effect on condition of the horse's health [2].

It is important for the oral examination to be performed in a controlled environment to avoid potential distractions that could stimulate the horse [3].
It is impossible (and dangerous) to properly examine a horse's mouth without the use of a full mouth gag (speculum) [4].

Appropriate ambient lighting is necessary, and good-quality intraoral illumination is essential to enable a thorough oral examination without causing clinician eye strain and fatigue $[5,6]$.

Equipment that satisfies and assists in the performance of a thorough oral examination includes adjustable halter and lead rope, dental halter (padded metal noseband) and rope, full-mouth speculum, light, bucket of dilute antiseptic, dose syringe, hand towel or paper towels, flexible fiber optic endoscope (if available) and timer [2]. 
Regular dental care will benefit the health and subsequent performance of the horse. Neglected dental care lead to colic which is the most common emergencies seen by equine practitioners Nationwide $[7,8]$.

Dentistry should be scheduled every 4 to 6 months for those horses that have teeth with occlusal areas not in wear and for those that are expected to perform at a high level [2].

The clinical signs associated with dental diseases are losing weight, dribbling grain, obvious shewing abnormalities, signs of facial tenderness, accumulating of grass or hay between the buccal gingiva and the cheek teeth (quidding), foul breath, excessive whole grain particles in feces and may be complicated with swelling on the lower jaw, maxilla or face and fistula [2,9].

Palpation through the cheeks may reveal food pocketing or detect major dental irregularities (such as a missing tooth or a large overgrowth) of the rostral three to four upper CT. Even if no such abnormality was palpated, the presence of pain (i.e. the horse pulling away or flinching) $[10,11]$.

Incisors teeth affections are divided to congenital and acquired disorders. Congenital disorders are: over bite [11], under bite [2], retained deciduous incisors [12] and Supernumerary permanent incisors [13]. Acquired disorders are incisor fractures [13], incisor occlusal surface abnormalities [14] and incisor diastmata [15].

Canine teeth affections are divided to congenital and acquired disorders. Congenital disorders are impacted tooth [2]. Acquired disorders are dental calculus (tartar) and dental infection [16].

Wolf teeth was found unerupted rostral to the teeth are commonly referred to as blind wolf teeth [2].

Cheek teeth affections are divided to congenital disorders, abnormal position, disorder of wear and disease of cheek teeth. Congenital disorders are retained deciduous cheek teeth and supernumerary cheek teeth [16]. Abnormal position are rostral positioning of the upper cheek teeth, disparity in the length of the cheek teeth rows and diastema(ta) [17]. Disorders of wear are sharp enamel points, step mouth [16], smooth mouth [14], wave mouth and shear mouth [18], hooks (ramps) [19] and Bit seat [20]. Diseases of cheek teeth are Trauma [21], fracture, Periodontal disease, den- tal tumors [15], dental decay [22], dental plaque (tartar) [2] and dental foreign body [23].

Treatment of sharp enamel points, rostral hooks and caudal hooks involved reducing the overlong portion of the tooth by power float and dealing with bit seat by rounding and carefully smoothing rostral corners of the upper, lower \#6s help in good performance in bit [2].

Removal of overgrown transverse ridges opposite diastmata may reduce food impaction [24].

In case of tooth fracture needed to be extracted [15].

Treatment of periodontal disease by cleaning out periodontal pockets by dental picks, scaler and rinsing equipment and packing pockets with an antibiotic gel [2].

Management of dental caries by cleaning and filling these areas with a composite [2].

\section{Aim of the Work}

Aim is to investigate the dental affections in horses of equestrian clubs and their possible treatment.

\section{Materials and Methods}

The present work was carried out in the period between "March 2015 to December 2016" the total number of examined horses was 354 horses, 92 horses had dental affections including 52 Equestrian horses, 34 Riding horses, 6 Funeral dragging horses. These horses were of both sexes and their ages were ranged between 3 years up to 22 years old. The examined horses were collected from Armed equestrian club, El Gzera club, El haram farms, Cairo stadium, El Shams club and Wadi Degla club.

The horses were divided according to usage into 3 groups, first group was used as equestrian horses, second group was used as riding horses and third group was used as funeral dragging horses. First group involved 52 equestrian horses, 49 male horses and $3 \mathrm{fe}$ male ones. Second group involved 34 riding horses, 13 male horses and 21 female ones. Third group involved 6 funeral dragging horses, they all are male horses.

The examined horses in this study were subjected to comprehensive study including history, type of horse (Equestrian, Riding 
or Funeral dragging) the time of last floating, post treatment care and follow-up.

The history of each examined horse was obtained from its owner. The type, sex, age, time of last floating was recorded.

Equipment used in this study of a thorough oral examination and treatment includes lead rope, high power headlamp ${ }^{1}$, full mouth speculum ${ }^{2}$, bucket of dilute antiseptic (Betadine ${ }^{3}$ ), dose syringe, hand towel, tooth elevator ${ }^{4}$, tooth extractor ${ }^{2}$, power float ${ }^{2}$ and smart cam $^{5}$ (Figure 1). If the horse does not relax or at least

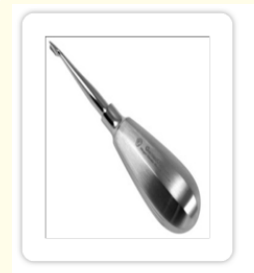

A-Tooth elevator

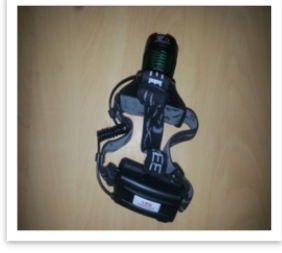

B-High power headlamp

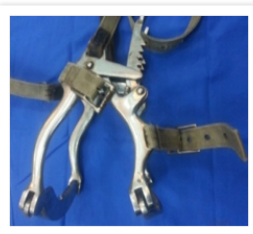

C-Oral speculum

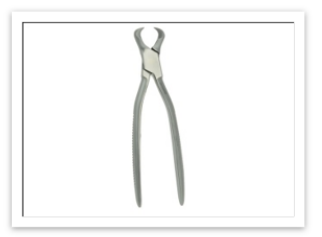

D-Tooth Extractor

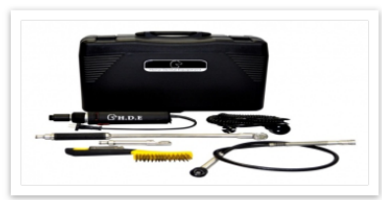

F-Equipment box and another

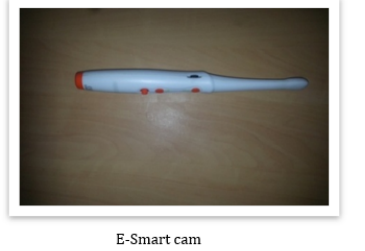

E-Smart cam

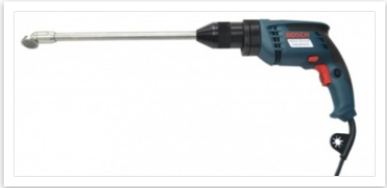

G-Power Float power float
Figure 1: Shows dental equipment that was used (A-Tooth elevator, B-high power headlamp, C-oral speculum, D-Tooth extractor, E-Smart cam and (F, G) power float).

tolerate the initial examination, we sedated the horse by (TranquiVed Xylazine $\mathrm{HCl}^{6}$ Injection or Sedivet $1 \%{ }^{7}$ ).
After care was consisted of injection of antibiotic that is against abroad spectrum of microbes streptopenicilline (pen\&strep ${ }^{8}$ ) at a dose of $1 \mathrm{mg} / 20 \mathrm{~kg}$ b.wt, I/M. for 3 days, injection of tetanus antitoxin ${ }^{9}$ vaccine in single dose of $6000 \mathrm{IU} /$ horse by S/C, usage of betadine and allamycine spray ${ }^{10}$ locally in case of injuries and tooth extraction daily 3 times for a week, avoid feeding horse before 12 hours after application of anesthesia and the horses were observed for minimum a week post treatment.

\section{Results}

In the present study, total number of examined horses was 354 horses, 92 horses had dental affections by ratio about $26 \%$. The prevalent dental affections in horses of Egyptian equestrian clubs that were found are dental tartar, sharp enamel points, dental caries, rostral hook, periodontal disease, diastmata, incisor tooth fracture, parrot mouth, bit seat, caudal hook and canine tooth fracture.

In dental tartar represented 75 horses with percentage $81.52 \%$. Treatment involved removal of tartar with curetting the tooth with tooth elevator and disinfection with tincture iodine $2 \%{ }^{11}$ (Figure 2 and 5).

Sharp enamel points were found in 39 horses with percentage $42.39 \%$. Treatment involved teeth should be floated by power float in stages, e.g. at three to six monthly intervals to prevent pulpar exposure, Digitally loose teeth can be extracted orally using tooth extractor in standing sedated horses, thorough washing of the mouth with Betadine and make stab wound in the hematomed hard palate helps horse to eat well (Figure 2).

Dental caries were recorded in 33 horses with percentage $35.86 \%$. Treatment involved cleaning the tooth well by tooth elevator, rinsing it by water then by tincture iodine $2 \%$. Degenerated tooth material should be debrided, repeating hexitol ${ }^{12}$ mouthwashes are the best treatment of dental caries and decreasing the proportion of dietary simple carbohydrates (grains such as barley and oats) regresses the disease (Figure 2).

\footnotetext{
${ }^{1}$ High power headlamp: Its chip is CREE T6 Led, made in China.

${ }^{2}$ Full-mouth speculum, tooth extractor and power float are produced by Horse Dental Equipment Company.

${ }^{3}$ Betadine: Its active principle is $5 \%$ providone iodine; It is used locally and produced by Ranbaxy Laboratories Limited, India.

${ }^{4}$ Tooth elevator: It is produced by GerVet USA company.

${ }^{5}$ Smart Cam: Digital oral camera, made in China, by ShanGhai Handy Medical Equipment co, model HD-110.

${ }^{6}$ TranquiVed Xylazine $\mathrm{HCl}$ : Its active principle is Xylazine Hcl, its dose is $0.5 \mathrm{ml} / 100 \mathrm{~kg}$.bw by I/V and produced by VEDCO.

${ }^{7}$ Sedivet 1\%: Its active principle is (Romifidine $\mathrm{Hcl}$ ), It is used in dose (0.4 - $1.2 \mathrm{~mL} / 100 \mathrm{~kg} \mathrm{~b}$ w.) through I/V and produced by Boehringer Ingelheim.

${ }^{8}$ Pen\&Strep: Its active principle is (Penicillin, Streptomycin), It is used I/M by dosage of $1 \mathrm{mg} / 20 \mathrm{~kg}$ and produced by Norbook.

${ }^{9}$ Tetanus antitoxins: Its active principle is (Antitetanic serum), It is used I/V by dosage of 6000IU and produced by Egypt.

${ }^{10}$ Allamycine spray: Its active principle is (Oxytetracycline spray), used locally and produced by Norbook, laboratories (GB) Limited.

${ }^{11}$ Tincture iodine 2\%: Its active principle is (Iodine, Sodium Iodide, Isopropyl Alcohol.), It is used locally and produced in Egypt.

${ }^{12} \mathrm{Hexitol}$ : Its active principle is (Chlorhexidine $\mathrm{HCl} 0.125 \%$ ), It is used locally as oral rinse and produced by Adeco.
} 
Periodontal disease was noticed in 18 horses with percentage $19.57 \%$. Treatment involved (Treat primary cause in case of secondary periodontal disease, cleaning out periodontal pockets, and packing pockets with an antibiotic gel (Doxirobe gel ${ }^{13}$ ). Widening the periodontal pocket helps in treating, recheck and retreat the pocket at intervals of 14 days until the pocket has healed and complete healing of the pocket occurred after 28 days, injection of the horse by anti-inflammatory drug (finadyne) and antibiotic (Pen\&Strep) for 5 days and feeding treated horse with easily digested food like hay, Egyptian clover and bran for 3 weeks. (Figure 9).

Rostral hook was observed in 15 horses with percentage $16.30 \%$. Treatment involved reducing the overlong portion of the tooth by using power float (Figure 4).

Diastmata was seen in 15 horses with percentage 16.30\%. Treatment involved cleaning out periodontal pockets, we make widening at the position of diastmata by tooth elevator and reduction the overlong portion of the opposite tooth and horse started to eat well (Figure 9).

Incisor tooth fracture was recorded in 6 horses with percentage $6.52 \%$. The tooth was remaining vital and continuing to erupt normally. Treatment involved antibiotic (Pen\&Strep ${ }^{14}$ ) and antiinflammatory (finadyne ${ }^{15}$ ). In the acute stages, but extraction the fractured incisors with exposed pulp by tooth extractor, following an incisor fracture, the opposing incisor(s) will overgrow into the site of the shortened or absent incisor(s) due to lack of attrition and these overgrowing incisors were floated twice yearly (Figure $6)$.

Parrot mouth was reported 3 horses with percentage $3.26 \%$. Dealing with this affection by reduction the overlong portion of the opposite tooth and horse started to eat well.

Bit seat was observed in 3 horses with percentage 3.26\%. It causes discomfort when it presses soft tissue in the mouth against the rostral surface of $06 \mathrm{~s}$. Treatment of this affection by making the bit seat rounded and comfortable (Figure 7).

Caudal hook was found in 3 horses with percentage 3.26\%. Treatment involved reducing the overlong portion of the tooth by using power float.

Canine tooth fracture was noticed in 1 horse with percent-

\begin{tabular}{|c|c|c|c|c|c|c|}
\hline $\begin{array}{l}\text { Type of } \\
\text { horse }\end{array}$ & \multicolumn{2}{|c|}{ Equestrian } & Riding & $\begin{array}{c}\text { Funeral } \\
\text { dragging }\end{array}$ & $\begin{array}{c}\text { Total } \\
\text { number }\end{array}$ & $\begin{array}{c}\text { Percentage } \\
\%\end{array}$ \\
\hline Number & \multicolumn{2}{|c|}{52} & 34 & 6 & 92 & \\
\hline \multirow{2}{*}{ Sex } & M & $\mathrm{F}$ & \begin{tabular}{|l|l}
$M$ & $F$
\end{tabular} & $\mathrm{~F}$ & & \\
\hline & 49 & 3 & \begin{tabular}{|l|l|}
13 & 21 \\
\end{tabular} & 6 & & \\
\hline \multicolumn{7}{|l|}{$\begin{array}{l}\text { Dental } \\
\text { affections }\end{array}$} \\
\hline $\begin{array}{l}\text { Dental } \\
\text { tartar }\end{array}$ & \multicolumn{2}{|c|}{33} & 36 & 6 & 75 & $81.52 \%$ \\
\hline $\begin{array}{l}\text { Sharp } \\
\text { enamel } \\
\text { points }\end{array}$ & \multicolumn{2}{|c|}{18} & 18 & 3 & 39 & $42.39 \%$ \\
\hline $\begin{array}{l}\text { Dental } \\
\text { caries }\end{array}$ & \multicolumn{2}{|c|}{18} & 12 & 3 & 33 & $35.86 \%$ \\
\hline $\begin{array}{l}\text { Periodontal } \\
\text { disease }\end{array}$ & \multicolumn{2}{|c|}{12} & 6 & - & 18 & $19.57 \%$ \\
\hline $\begin{array}{l}\text { Rostral } \\
\text { hook }\end{array}$ & \multicolumn{2}{|c|}{6} & 6 & 3 & 15 & $16.30 \%$ \\
\hline Diastmata & \multicolumn{2}{|c|}{9} & 6 & - & 15 & $16.30 \%$ \\
\hline $\begin{array}{l}\text { Incisor } \\
\text { tooth } \\
\text { fracture }\end{array}$ & \multicolumn{2}{|c|}{3} & 3 & - & 6 & $6.52 \%$ \\
\hline $\begin{array}{l}\text { Parrot } \\
\text { mouth }\end{array}$ & \multicolumn{2}{|c|}{3} & - & - & 3 & $3.26 \%$ \\
\hline Bit seat & \multicolumn{2}{|c|}{3} & - & - & 3 & $3.26 \%$ \\
\hline $\begin{array}{l}\text { Caudal } \\
\text { hook }\end{array}$ & \multicolumn{2}{|l|}{ - } & 3 & - & 3 & $3.26 \%$ \\
\hline $\begin{array}{l}\text { Canine } \\
\text { tooth } \\
\text { fracture }\end{array}$ & \multicolumn{2}{|l|}{ - } & 1 & - & 1 & $1.087 \%$ \\
\hline
\end{tabular}

Table 1: Include groups of horses, number, sex, type of dental affections and their percentage.

age $1.087 \%$. Canine tooth extraction is the best treatment by tooth extractor and suturing gum with absorbable sutures (Figure 8).

All cases presented in this investigation showed appearance of the affections in males more than females except in caudal hook affection that presented in females only.

\footnotetext{
${ }^{13}$ Doxirobe gel: Its active principle is (Doxycycline hyclate 8.5\%), It is used locally and produced by Zoetis US.

${ }^{14}$ Pen\&Strep: Its active principle is (Penicillin, Streptomycin), It is used I/M by dosage of $1 \mathrm{mg} / 20 \mathrm{~kg}$ and produced by Norbook.

${ }^{15}$ finadyne: Its active principle is (Flunixin meglumine), It is used I/M or I/V by dosage of $1 \mathrm{ml} / 45 \mathrm{~kg} \mathrm{~b}$ w. and produced by Intervet/Schering-Plough Animal Health.
} 
It found also the recurrence of presence dental tartar after 3 months and well seen after 6 months, the recurrence of presence sharp enamel points after 4 months and well observed after 6 months, the recurrence of presence rostral hook after 9 months and well observed after 12 months, the recurrence of presence bit seat after 9 months and well observed after 12 months, Recurrence of presence caudal hook after 12 months and well observed

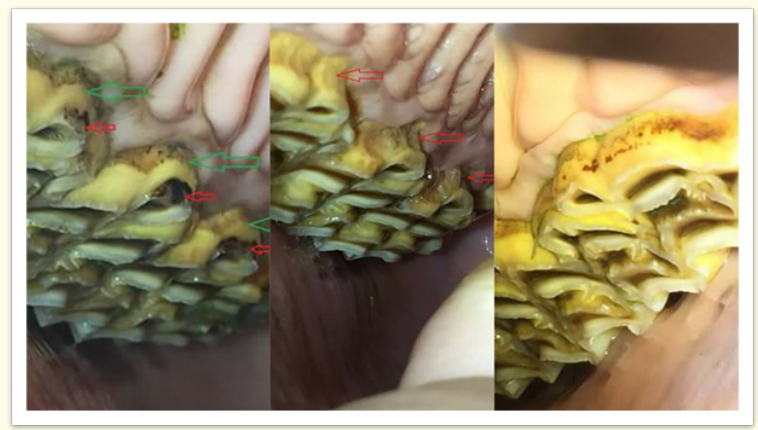

Figure 2: Shows dental tartar, dental decay and sharp enamel points, in cheek teeth (108 - 111) 4th pre- molar till third molar in riding horse, Female, 12 years old. After treatment: new healthy layer and decayed area is disappeared in "c image".
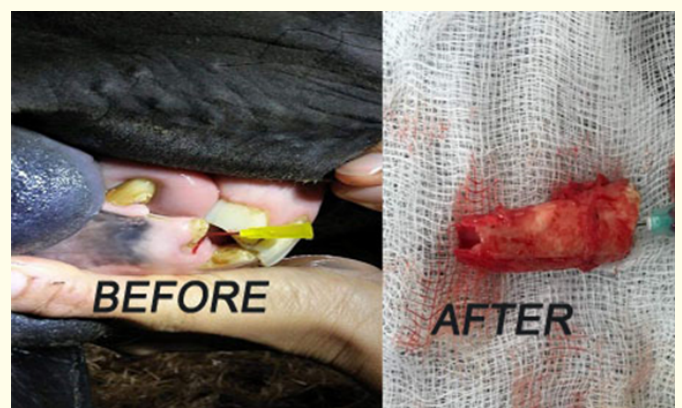

Figure 3: Shows a very painful pulp infection with fractured mandibular incisor (403) in young horse approximately 3 years, before and after treatment.

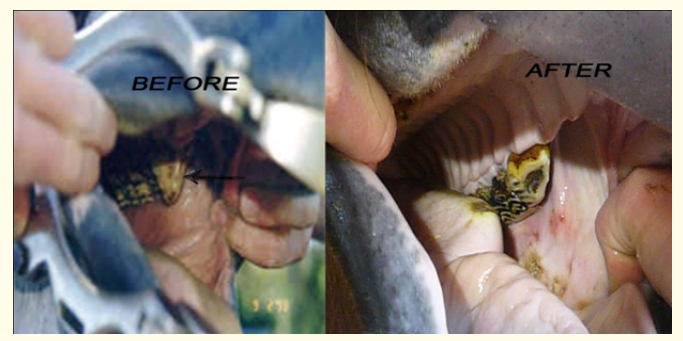

Figure 4: Shows rostral hook in (206) 2nd pre-molar in equestrian horse 13 years old, before and after treatment.

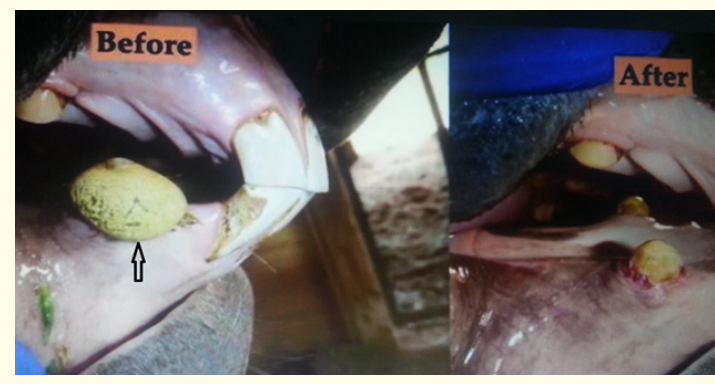

Figure 5: Shows tartar in lower right canine tooth (404) in riding horse, 12 years old, before and after treatment.

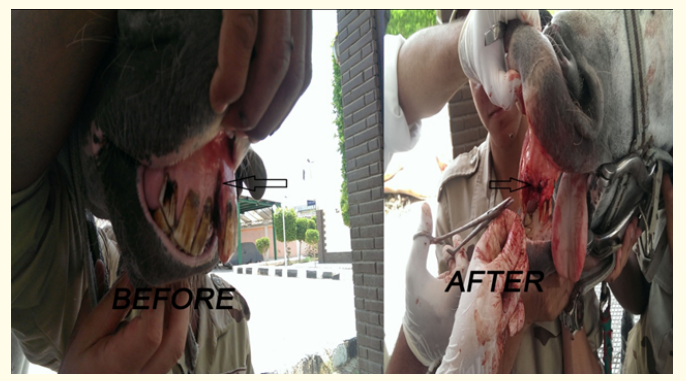

Figure 6: Shows fissure in gum because of hitting irony door of its stable and dental trauma in $(201,202)$ in equestrian horse, 13 years old, before and after treatment.

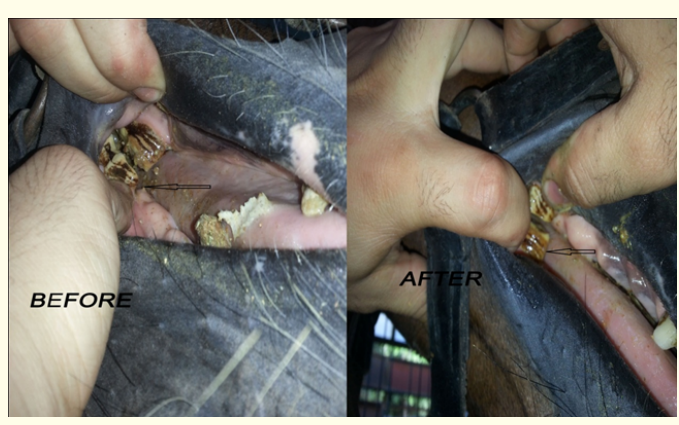

Figure 7: Shows (bit seat) and dental tartar in $(106,406) 2$ nd pre molar in equestrian horse, 11 years old, before and after treatment.

A

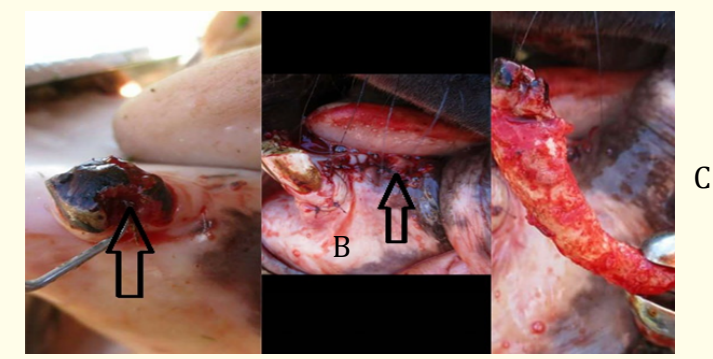

Figure 8: Shows fracture in lower left canine tooth (304) in riding horse, male, 12 years old. We extract this tooth by tooth extractor and suturing gum with absorbable sutures as in (B, C) images. 


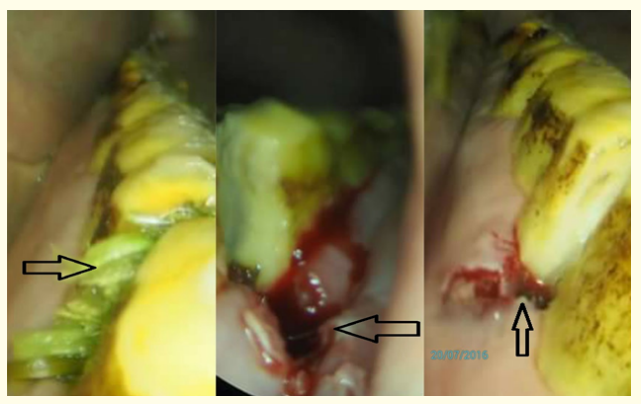

Figure 9: Shows diastmata and periodontal disease between “308-309" 4th pre molar till 3rd molar in equestrian horse, male 16 years old, before and after treatment.

after 15 months. Complete recovery from all dental affections was occurred satisfactory without complications and colic. (Figure 2-9

\section{Discussion}

In the present study, total number of examined horses was 354 horses, 92 horses had dental affections by ratio about 26\%.The prevalent dental affections in Egyptian equestrian clubs that were found are dental tartar, sharp enamel points, dental caries, rostral hook, periodontal disease, diastmata, incisor tooth fracture, parrot mouth, bit seat, caudal hook and canine tooth fracture, while BEVA [1] reported that dental diseases were up to $10 \%$ of dental related-work.

Sharp enamel points were recorded in (39) horses from 92 horses. These results were met with that obtained by Becker [25].

It was found that if the horse does not relax or at least tolerate the initial examination, sedation is indicated by (TranquiVed Xylazine $\mathrm{HCl}$ Injection or Sedivet 1\%) and this is agreed with that of Brigham and Duncanson [26] and Ramzan [27]. In the same time pence [2] added that detomidine, xylazine and butorphanol are excellent sedatives for dental examinations and procedures to prevent ataxia.

Clinically, foul breath and halitosis was one of signs that were found in dental tartar, sharp enamel points, dental caries, rostral hook, periodontal disease, diastmata, incisor tooth fracture, bit seat, caudal hook and canine tooth fracture, this result was coincide with that mentioned by Pence [2]. On the other hand Dixon., et al. [21] and Dixon., et al. [28] indicated that halitosis may be present only if widespread periodontal disease, or less commonly, when advanced dental caries is present.
It was found that dental tartar, sharp enamel points, dental caries, periodontal disease, diastmata, bit seat and caudal hook caused equine colic and these results were similar to that reported by Pence [2]. Contrarily, Timothy and Joseph [22] reported that dental caries and sharp enamel points only, are predisposing factors for colic in horses.

In the present work, usually used in a thorough oral examination lead rope, source of light, bucket of dilute antiseptic (Betadine), dose syringe, hand towel, tooth elevator, tooth extractor, power float and smart cam and this is agreed with that of Pence [2]. In the same time Dacre [29] added that the use of a long dental mirror can reveal subtle lesions.

Treatment of dental tartar involved removal of tartar, curetting the tooth by tooth elevator and disinfection by tincture iodine $2 \%$. On the other hand, Dixon and Dacre [16] preferred using strong forceps only and the above-noted periodontal disease will then usually regress, due to the ability of equine periodontal membranes to reform.

In the present work, treatment of sharp enamel points, rostral hook and caudal hook by rasping the overlong portion of the tooth by power float, these results were met with Pence [2].

As regard, treatment of dental decay involved cleaning the tooth well by tooth elevator, rinsing it by water then by tincture iodine $2 \%$, degenerated tooth material should be debrided, repeating hexitol mouthwashes is the best treatment of dental caries and decreasing the proportion of dietary simple carbohydrates (grains such as barley and oats) slow down progression of the disease. Pence [2] added that cleaning and filling these decayed areas with a- composite may arrest the decomposition of the tooth each carious lesion must be approached as a unique situation and evaluated for severity of decomposition of the infundibular enamel, but our treatment was successful.

Concerning the treatment of periodontal disease involved (Treat primary cause in case of secondary periodontal disease, cleaning out periodontal pockets, and packing pockets with an antibiotic gel (Doxirobe gel). Widening the periodontal pocket helps in treating this disease, recheck and retreat the pocket at intervals of 14 days until the pocket has healed, injection of the horse by anti-inflammatory drug (finadyne) and antibiotic (Pen\&Strep) for 5 days and these results were coincided with obtained by Pence [2].

In treatment of diastmata, make widening at the position of distemata by tooth elevator and reduction the overlong portion of the opposite tooth by power float and this is in agreeable with that of 
Barakzai and Dixon [24], furthermore, Dixon and Dacre [16] added that specialized burrs have recently been developed to widen diastmata at the occlusal surface to help limit food trapping and are best used after radiographic evaluation (open-mouth projections) of diastmata to help reduce the risk of iatrogenic pulpar exposure during such procedures.

Management of incisor tooth fracture and canine tooth fracture can be successfully done by extraction the fractured tooth and these results were similar to Pence [2].

Belong of the treatment of bit seat, making the bit seat rounded by power float, and this result was agreed with the result mentioned by Pence [2].

In this work, over bite management can be done by reducing the overlong portion of the opposite tooth by power float and this is met with that of Dixon., et al. [21] and Easley [11] added that over jet in foals can be treated by orthodontic therapy, i.e., wiring the upper incisors to the upper CT to restrict growth of the pre maxilla and maxilla.

\section{Conclusion}

All dental affections were recorded in male horses more than female except in case of caudal hook affection. Recurrence of dental tartar and sharp enamel points occurred after 3 to 4 months. It was found that dental tartar is the most prevalent dental affection in this study. Making stab wound indicated in case of the hematoma of the hard palate that resulted from sharp points of teeth

\section{Bibliography}

1. BEVA. "British Equine Veterinary Association survey of equine disease". Veterinary Record 77 (1965): 528-538.

2. Pence P. "Equine Dentistry: A Practical Guide". Published by Lippincott Williams and Wilkins, $2^{\text {nd }}$ edition (2002).

3. Menzies RA., et al. "Essential considerations for equine oral examination, diagnosis, and treatment". Journal Veterinary Dentistry 28 (2011): 204-209.

4. Scrutchfield WL. "Dental prophylaxis". GJ Baker, J.Easley (Eds.), Equine Dentistry (first edition.), W.B. Saunders, London (1999): 185-205.

5. Young JM., et al. "Intraoral dental lights: test and evaluation". Journal of Prosthetic Dentistry 57.1 (1987): 99-107.

6. Preston JD., et al. "Light and lighting in the dental office". Dental Clinics of North America 22.3 (1978): 431-451.
7. Lowder MQ. "Floating teeth". Veterinary Record 77 (2001): 528-538.

8. Lowder MQ and Mueller POE. "Dental disease in geriatric horses". Veterinary Clinics of North America: Equine Practice (1998): 365-380.

9. O'Connor JJ. "Dollars Veterinary Surgery (second edition)". Balliere Tindall and Cox, London (1930): 481-491.

10. Scrutchfield WL and Schumacher J. "Examination of the oral cavity and routine dental care". Veterinary Clinics of North America - Equine Practice (1993): 123-131.

11. Easley J. "Dental and oral examination". GJ Baker, J Easley (Eds.), Equine Dentistry (first ed.), W.B. Saunders, London (1999): 107-126.

12. Alexander K., et al. "Incisor extraction in a horse by a longitudinal forage technique". Equine Veterinary Education (2001): 179-182.

13. Dixon PM., et al. "Equine dental disease part 1: a long-term study of 400 cases: disorders of incisor, canine and first premolar teeth". Equine Veterinary Journal (1999): 369-377.

14. Kempson SA., et al. "The effect of three types of rasps on the occlusal surface of equine CT: a scanning electron microscopic study". Journal of Veterinary Dentistry (2003): 19-27.

15. Dixon PM and Collins NM. "Diagnosis and management of equine diastmata". Clinical Techniques in Equine Practice 4.2 (2005): 148-154.

16. Dixon PM and Dacre I. "A review of equine dental disorders". The Veterinary Journal 169.2 (2005): 165-187.

17. Carmalt JL. "Understanding the equine diastema". Equine Veterinary Education (2003): 34-35.

18. Peter D., et al. "Merck Manual for Pet Health, Pet Owners, Horse Disorders and Diseases, Digestive Disorders of Horses" (2011).

19. Koontz RH. Chief Executive Officer, Conley and Koontz Equine Hospital (2016): 183.

20. Bettiol N and Dixon PM. "An anatomical study to evaluate the risk of pulpar exposure during mechanical widening of equine cheek teeth diastmata and 'bit seating'". Equine Veterinary Journal 43.2 (2011): 163-169. 
21. Dixon PM., et al. "Equine dental disease". Part 3: a long-term study of 400 cases: disorders of wear, traumatic damage and idiopathic fractures, tumours and miscellaneous disorders of the cheek teeth". Equine Veterinary Journal (2000a): 9-18.

22. Timothy AOO and Joseph FA. "Do dental abnormalities predispose horses to colic?" Journal of Veterinary Medicine and Animal Health 6.7 (2014): 192-197.

23. Saulez MN., et al. "Perforation of the gastrointestinal tracts of four horses by metallic wires". Veterinary Record 164 (2009): 86-88.

24. Barakzai SZ and Dixon PM. "A study of open-mouthed oblique radiographic projections for evaluating lesions of the erupted (clinical) crown". Equine Veterinary Education (2003): 143148.

25. Becker E., et al. "Handbook of special pathological anatomy of pets (third edition.)". Verlag Paul Parey Berlin (1962): 121133.

26. Brigham EJ and Duncanson G. "Case study of 100 horses presented to an equine dental technician in the UK". Equine Veterinary Education (2000b): 63-67.

27. Ramzan PH. "The need for chemical restraint while performing routine dental procedures using a full mouth speculum: a retrospective study of 581 examinations". Equine Veterinary Education (2002): 30-32.

28. Dixon PM., et al. "Equine dental disease part 4: a long-term study of 400 cases: apical infections of cheek teeth". Equine Veterinary Journal (2000b):182-194.

29. Dacre IT. "Equine dental pathology". In: Baker GJ, Easley J. (Editions.), Equine Dentistry, second edition. W.B. Saunders, London, in press (2004).

\section{Assets from publication with us}

- Prompt Acknowledgement after receiving the article

- Thorough Double blinded peer review

- Rapid Publication

- Issue of Publication Certificate

- High visibility of your Published work

Website: www.actascientific.com/

Submit Article: www.actascientific.com/submission.php

Email us: editor@actascientific.com

Contact us: +919182824667 